\title{
A crise contemporânea e os impactos no mundo do trabalho: resistências e desafios às contrarreformas
}

Claudia Gomes ${ }^{1}$

Gonzalo Rojas ${ }^{2}$

Inez Stampa ${ }^{3}$

Em uma reflexão da Sagrada Família, Marx (2011) não só anteviu a essência do modo de produção capitalista ao indicar a perda da natureza humana do proletariado moderno, como sinalizou o seu caráter dialético, que resulta do movimento revolucionário, a tarefa de recuperar, por meio da luta de classes dos trabalhadores, a humanidade subtraída.

Não temos dúvidas que todas e cada uma das características do capitalismo na atualidade confirmam de maneira imperativa as deduções teóricas de Marx sobre o método de produção de mais-valia relativa e absoluta, de subtração das faculdades produtivas do trabaIhador pela burguesia através da maquinaria (novas tecnologias), cujo resultado é a redução do trabalhador, em termos teóricos, a simples força abstrata de trabalho que serve a produtos materiais de diversas índoles, a exemplo dos produtos digitais que se manifestam, na prática, numa maior exploração.

À vista disso, a indústria 4.0 (ANTUNES, 2019) ou Quarta Idade da Máquina (ALVES, 2011) é a expressão cabal da contradição entre a substituição do trabalho vivo pelo trabalho morto, que amplia, a largos passos, um exército de trabalhadores desempregados e joga na vala da subalternidade e da precarização as condições de vida da classe trabalhadora. Reproduzidos aos montes, pelo trabalho informal, intermitente, trabalho do tipo crowdwork, uberizado, remoto, etc.; os no- 
vos supérfluos se agigantam e são subsumidos a trabalhos instáveis, a novas formas de organização e (des)regulamentação do trabalho, a precarização laboral de diversas ordens, inclusive as que afetam as mulheres trabalhadoras, coletivos LGBT e juventude que, sem garantias trabalhistas, se encontram totalmente desprovidos de proteção social. Este aumento da composição orgânica do capital, pelo aumento da proporção entre trabalho morto na sua relação com o trabalho vivo, que gera mais-valia, aumenta, aprofunda a crise capitalista e faz cair a taxa de lucro dos capitalistas. Nesta situação, os capitalistas tentam descarregar o preço da crise sobre os trabalhadores, e, simultaneamente, como resposta a crise geral do capitalismo de 2008.

A extração do excedente da força de trabalho se amplia em larga escala com o avanço da crise mundial e a recessão generalizada, o que nos faz recordar as lições de Marx sobre a utilidade concreta do exército industrial de reserva para a acumulação, que serve como depósito de força de trabalho explorável e sempre disponivel para as necessidades expansivas do capital (CRESPO, 2015). Cabe explicitar que a lei geral da acumulação capitalista, da maquinaria à grande indústria, se funda na capacidade de forjar uma força de trabalho excedente, ou seja, "[...] uma população trabalhadora adicional relativamente supérflua ou subsidiária, ao menos no concernente às necessidades de aproveitamento por parte do capital" (MARX, 1984, p. 199).

É possível dizer, então, que as necessidades vitais do capital se renovam diariamente e a voracidade de obtenção de lucro e exploração da força de trabalho se compõe de uma capacidade extraordinária de reprodução, que nele entram pelo metabolismo: à medida que o trabalhador cria riqueza, essa se torna uma força do capital; sendo a única maneira possível de garantir internamente a sua acumulação, o aumento da produção de excedente através da exploração da força de trabalho, implica "[...] na elevação da taxa de mais-valia, seja por arrocho salarial e/ou extensão da jornada de trabalho, em associação com o aumento da intensidade do trabalho" (CARCANHOLO; NAKATANI, 2007, p. 11). 
Os leitores dessa tradição teórica sabem que atravancado o movimento expansivo de acumulação o capital empreende uma batalha mundial para restaurar a rentabilidade e impulsionar as taxas de lucro, como mencionamos. Na medida em que a taxa de lucro do capital é o "aguilhão da produção capitalista" sua queda retarda o desenvolvimento de novos capitais autônomos e se apresenta, portanto, como ameaça ao desenvolvimento do processo de produção capitalista. Sua queda dá origem à superprodução, especulação, crises, capital supérfluo e população supérflua. A elucidação da crise está, portanto, na lei da queda tendencial da taxa de lucro, que "de fato é a conclusão de O Capital [...] seu caráter tendencial é o marco em que se operam oscilações e irregularidades" (ARRIZABALO MONTORO, 2020, p. 68).

Com o avanço da crise orgânica do capitalismo mundial, em termos gramscianos, uma crise econômica, política e social que se aprofunda com a crise sanitária, as determinações para as economias nacionais, através da internacionalização do capital, têm preparado o terreno para novas condições de ajustes e contrarreformas, feitas no sentido de retomar as taxas de lucro e valorização do capital com avanços destrutivos para a própria reprodução do trabalhador, que se vê impactado nas suas condições de vida e trabalho cada vez mais precarizado e desprovido de proteção social. Os efeitos mais imediatos dessa crise se revelam nos ataques à organização dos trabaIhadores, na flexibilização de direitos trabalhistas e previdenciários e na diminuição dos fundos públicos destinados aos direitos sociais. $O$ intento é, também, dividir a classe trabalhadora entre empregados e desempregados, efetivos e terceirizados, nativos e migrantes, além de fortalecer o patriarcalismo e o racismo para oprimir mais com o objetivo de explorar melhor.

É fato inconteste que a grave crise econômica que caracteriza o atual contexto socioeconômico tem sido marcada por sucessivas reformas trabalhistas, que vem conformando novas relações de trabalho, acompanhada de altos índices de desemprego, com significativa degrada- 
ção das condições de trabalho e um aumento quantitativo de trabalho precário e irregular. Isso teve a cumplicidade das direções das Centrais sindicais, como um fenômeno político mundial, resultado da conciliação de classes, conduzidos pelos partidos progressistas de esquerda.

A agudização da crise financeira, agravada pela pandemia da Covid-19, desencadeou impactos sociais profundos nos países em escala global. De acordo com o último estudo conjunto realizado pela Comissão Econômica para a América Latina e o Caribe (Cepal) e pela Organização Internacional do Trabalho (OIT), as projeções para esses países, cuja composição da força de trabalho, historicamente, é marcada pela precarização e informalização do trabalho, são ainda mais drásticas (CEPAL; OIT, 2020).

Doze anos depois do crash que desequilibrou a maior potência imperialista, o mundo volta a experimentar uma nova crise sem precedentes e com graves consequências para o segmento específico da classe trabalhadora que se encontra à margem do sistema de proteção social. Nas análises de Antunes (2020), trata-se de uma massa de trabalhadores em um fogo cruzado; entre a impossibilidade de isolamento social e a necessidade de trabalhar para sobreviver, realidade letal e peculiar ao metabolismo (antissocial) do capital.

Como contratendência, desde a luta de classes, observamos as maiores mobilizações de massas nos Estados Unidos da América (EUA) dos últimos 50 anos, com dois elementos importantes: trabalhadores brancos apoiam a pauta do movimento negro com greves de apoio em numerosas cidades e a crítica contundente à polícia, braço repressivo do Estado, sendo expulsos dos sindicatos dos trabalhadores e, em algumas cidades, exigindo a sua dissolução. Mesmo que possa ser capitalizada no marco eleitoral como um triunfo do Partido Democrata, um dos partidos imperialistas mais antigos do mundo, o que não é uma saída para os trabalhadores e o povo negro, considerando que Trump pode ser derrotado, o que, com certeza, terá repercussões no Brasil e na extrema direita.

Em agudo contraste com os períodos anteriores de crise do capital, em que era possível deslocar contradições e retomar a expansão, no 
contexto de crise estrutural, que começamos a experimentar a partir da década de 1970 e que se prolonga com características específicas nesse contexto de pandemia, o desemprego torna-se característica exponencialmente dominante. O grave quadro de trabalhadores despejados do mercado de trabalho, combinado à necessidade de ter de escolher entre perder o emprego ou a própria vida, vem incrementando as desigualdades sociais já existentes e repondo, à luz do dia, novas faces de trabalho precário.

As novas configurações do mundo do trabalho assumem um padrão em que a flexibilidade é a palavra de ordem. Com isso, observa-se no capitalismo contemporâneo a expansão de unidades produtivas cada vez mais "enxutas", onde são constantes as reduções de postos de trabalho e o aumento de trabalhadores subutilizados (IBCE, 2019). É através desse novo padrão produtivo que o capital consegue ampliar ao máximo a taxa de mais-valia, por meio da precarização do trabalho, com a diminuição da quantidade de trabalhadores diretos vinculados às empresas, o aumento da rotatividade de trabalhadores, a diminuição da remuneração, entre outros aspectos que só pioram as condições de trabalho e o acesso aos direitos dos trabalhadores.

Os dados da Pesquisa Nacional por Amostra de Domicílios Contínua (Pnad Contínua), do Instituto Brasileiro de Geografia e Estatística (IBCE) revelaram que, somente no primeiro trimestre de 2020 a taxa de desemprego aumentou de $11,2 \%$ para 12,6\%, correspondendo a 900 mil vagas de emprego suprimidas, frente ao trimestre anterior. Com isto, chegamos a um patamar de 13 milhões de pessoas desempregadas no país, dessas, 4,8 milhões estão em situação de desalento (já estavam desempregados e desistiram de procurar emprego).

Importa destacar que do total da população ocupada brasileira cerca de 40\% é informalizada. Trata-se de 39,5 milhões de trabalhadores à margem do sistema de proteção social. De acordo com o IBCE (2019), o contingente de trabalhadores informais apresentou uma tímida queda $(1,1 \%)$, caindo de $41 \%$ para $39,9 \%$ em relação ao trimestre 
anterior, provavelmente ocorrido às custas do aumento de trabalhadores subutilizados que avançou 5,6\%, correspondendo a 1,5 milhão de pessoas a mais trabalhando sob condições precárias. Estamos nos referindo aos trabalhos intermitentes, uberizados, prestadores de serviços, temporários, por conta própria e autônomos (não formalizados), formas de trabalho que, nos últimos cinco anos, elevaram o índice de ocupação no país, mas não diminuíram o grau de exploração da força de trabalho dos que permanecem em atividade.

Nesse novo universo em que ganha centralidade a figura do infoproletariado/cibertariado/proletariado digital (ANTUNES, 2019), a burguesia trata de desenvolver estratégias para acelerar a produtividade do trabalho em grau extremo, instituindo o home office, teletrabalho, delivery, empreendedorismo digital dentre outras formas mediadas por plataformas digitais como imperativo de produção mecanizada e de sobrevivência do capital. Mesclam-se múltiplas faces da informalidade, situadas, predominantemente, na esfera da circulação e da venda de serviços e mercadorias, enquanto potencial meio de valorização do capital (LIMA, 2012). E a tendência recente, com o incremento das novas tecnologias, é que o capitalista dependa cada vez menos do adiantamento de capital para a efetivação do valor.

Encontramo-nos frente a uma nova classe trabalhadora que tem caraterísticas determinadas em todo o planeta, sendo mais feminina na sua composição e com peso no setor de serviços, que é cada vez mais estratégico no capitalismo, e está enormemente precarizada e fragmentada (DEL CAÑO, 2019).

Nessa direção, as medidas de ajuste que já vinham em processo enquanto alternativa de contratendência à queda das taxas de lucro do capital, feitas no sentido de contornar a crise brasileira, se expressam no sentido da diminuição dos diretos dos trabalhadores, redução do acesso a serviços públicos, subtração do financiamento de direitos sociais, que não chegam a custar sequer $1 \%$ do total do Produto Interno Bruto (PIB) no Brasil. Nela, a realidade se torna mais complexa, porque 
a crise de valorização do capital, levada às ultimas consequências pela internacionalização da produção, exige uma alteração da acumulação de capitais na república financeira brasileira, fazendo avançar as linhas de força do imperialismo no país.

Todo esse cenário de crise agravada pela Covid-19 parece ter tomado proporções assustadoras, com o desaparecimento de milhares de brasileiros acometidos por síndrome respiratória aguda grave e a previsão de uma inflexão econômica de aproximadamente cinco pontos percentuais negativos no PIB (BANCO MUNDIAL, 2020). Além do baixo crescimento, a desigualdade e a vulnerabilidade social certamente serão potencializadas, desencadeando uma tendência crescente ao aprofundamento da pobreza, alcançando 34,7\% e $13 \%$ da população, respectivamente, o que equivale à aproximadamente 300 milhões de pessoas pauperizadas.

Portanto, o presente dossiê pretende aprofundar a discussão sobre o avanço da crise mundial que impõe tensões crescentes sobre a força de trabalho e à organização dos trabalhadores, tendo como base o processo histórico de contrarreformas que vem conformando o campo do trabalho, segundo a perspectiva da luta de classes no contexto tanto latino-americano e brasileiro, quanto europeu.

Tendo como ponto central de preocupação as reflexões sobre o trabalho e o campo de lutas pela emancipação das formas e relações de exploração, opressão e dominação vigentes, os artigos trazem contribuições que abordam, do ponto de vista crítico, a crise capitalista contemporânea e seus impactos no trabalho, em seus aspectos políticos, econômicos, sociais e culturais, além das novas formas de organização e (des)regulamentação do trabalho; precarização laboral de diversas ordens, inclusive as que afetam as mulheres trabalhadoras, coletivos LGBT e juventude; debilidades e perspectivas de atuação coletiva de trabalhadoras e trabalhadores; discussões acerca de aspectos trabalhistas e previdenciários, resistências e possibilidades de saída política às contrarreformas do capital. 


\section{Referências}

ALVES, Giovanni. Trabalho e subjetividade: o espírito do toyotismo na era do capitalismo manipulatório. São Paulo: Boitempo, 2011.

ANTUNES, Ricardo (Org.). Proletariado digital, serviços e valor. In: Riqueza e miséria do trabalho no Brasil IV. 1 ed. São Paulo: Boitempo, 2019.

ANTUNES, Ricardo. Coronavírus: o trabalho sob fogo cruzado. Coleção Pandemia Capital. eBook. São Paulo: Boitempo, 2020.

ARRIZABALO MONTORO, Xabier. Imperialismo, destruição das forças produtivas e crise crônica do capitalismo: O Capital, um instrumento essencial para entender a atual economia mundial. In: Cláudia M. Costa Gomes (Org.). A Crise e os limites históricos do capitalismo. Curitiba: Ed. Appris, 2020.

BANCO MUNDIAL. A economia em tempos de Covid-19: relatório semestral sobre a região da América Latina e Caribe. 2020. Disponível em: https://openknowledge.worldbank.org/handle/10986/33555. Acesso em: 30 jun. 2020.

CARCANHOLO, Reinaldo; NAKATANI, Paulo. Capitalismo especulativo y alternativas para a América Latina. Buenos Aires, Herramienta, 2007.

COMISIÓN ECONÓMICA PARA AMÉRICA LATINA Y EL CARIBE (CEPAL). Panorama Social de América Latina. Santiago: CEPAL, 2019. Disponível em: https://repositorio.cepal.org/bitstream/handle/11362/44969/5/S1901133_ es.pdf. Acesso em: 25 jun. 2020.

COMISIÓN ECONÓMICA PARA AMÉRICA LATINA Y EL CARIBE (CEPAL). ORGANIZAÇÃO INTERNACIONAL DO TRABALHO (OIT). Coyuntura Laboral en América Latina y el Caribe. El trabajo en tiempos de pandemia: desafíos frente a la enfermedad por coronavirus (COVID-19). Informe Cepal/OIT $n^{\circ}$ 22, maio de 2020. Disponível em: https://www.cepal.org/es/publicaciones/ 45557-coyuntura-laboral-america-latina-caribe-trabajo-tiempos-pandemia-desafios-frente. Acesso em: 2 set. 2020.

DEL CAÑO, Nicolás. Rebelde o precarizada. Vida y futuro de la juventud en tiempos de FMI, de los noventa y la era Macri. Ciudad Autónoma de Buenos Aires: Planeta; 2019.

CRESPO, Mario Del Rosal. El capitalismo sueco y los límites del socialismo reformista: una crítica marxista del model de Rhen-Meidner (1932-1983). Tesis doctoral. Universidad Complutense de Madrid, 2015, 537 p. 
INSTITUTO BRASILEIRO DE GEOGRAFIA E ESTATÍSTICA (IBGE). Síntese de indicadores sociais 2019. Disponivel em: https://agenciadenoticias.ibge.gov. br/media/com_mediaibge/arquivos/f1404e8068f13a84a53a9d0b7ca997e3. pdf. Acesso em: 5 set. 2020.

LIMA, Fabiana Alcântara. Crise contemporânea, microcrédito e trabalho informal: uma análise da tendência desenvolvimentista das políticas sociais. Dissertação de Mestrado em Serviço Social. João Pessoa, Universidade Federal da Paraíba, 2012. 226 p.

MARX, Karl. O Capital: Crítica da Economia Política. Livro I, Tomo II. São Paulo: Abril Cultural, 1984.

MARX, Karl. O Capital. Crítica da Economia Política. Livro I. O processo de produção do capital. São Paulo: Boitempo; 2013.

MARX, Karl; ENGELS, Friedrich. A Sagrada Família. (Trad. Marcelo Backes). São Paulo: Boitempo, 2011.

\section{Notas}

1 Pós-doutora pela Universidad Complutense de Madrid. Professora Associada da Universidade Federal da Paraíba, Programa de Pós-Graduação em Serviço Social, Coordenadora do Grupo de Estudos e Pesquisa em Economia Política e TrabaIho (CEPET), cadastrado no DGP/CNPq. ORCID: https://orcid.org/0000-00029366-3107. Contato: claudia.gomes@academico.ufpb.br.

2 Professor Dr. Ciência Política, Unidade Acadêmica de Ciências Sociais (UACS), Programa do Pós-graduação em Ciência Política (PPCCP) e no Programa de Pós-graduação em Ciências Sociais (PPCCS) da Universidade Federal de Campina Grande (UFCG), Campina Grande, Paraíba. Brasil. ORCID: https://orcid.org/00000003-2009-4772. E-mail: gonzalorojas1969@hotmail.com.

3 Doutora em Serviço Social. Professora do Departamento de Serviço Social da Pontifícia Universidade Católica do Rio de Janeiro (PUC-Rio). Coordenadora do Grupo de Pesquisa Trabalho, Políticas Públicas e Serviço Social (TRAPPUS), cadastrado no DCP/CNPq Brasil. Bolsista de Produtividade em Pesquisa do CNPq. ORCID: https://orcid.org/0000-0003-3770-1129. inezstampa@gmail.com. 


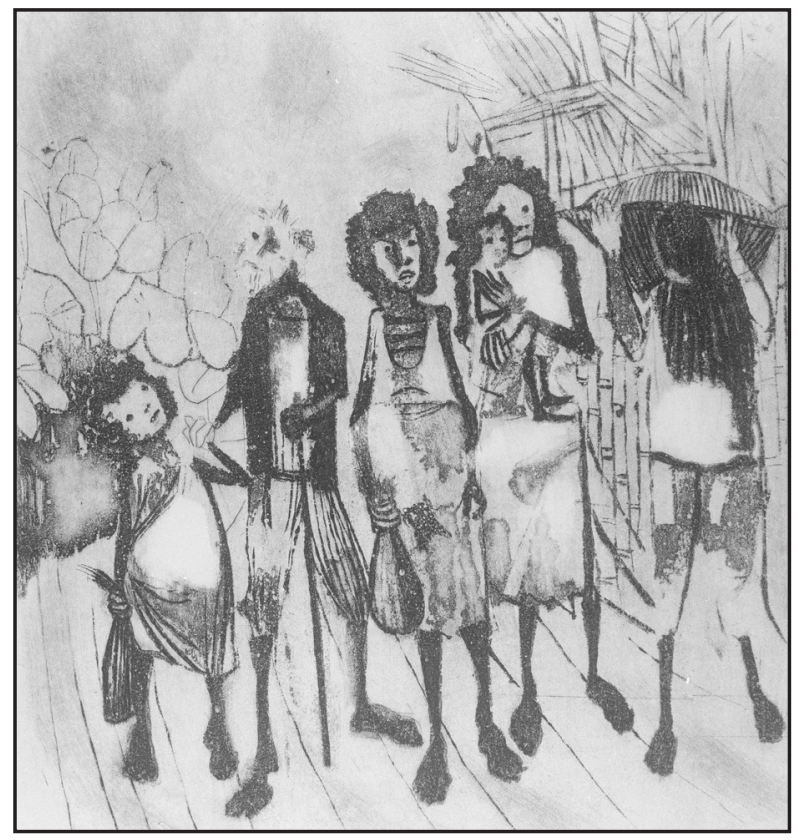

IMAGEM DA CAPA: RETIRANTES (1959)

Gravura

Água Forte / papel $(23,5 \times 21,5 \mathrm{~cm})$

Rio de Janeiro, Rio de Janeiro, Brasil

Imagem do Acervo do Projeto Portinari

Reprodução autorizada por João Cândido Portinari 